\title{
The Effectiveness of the Specific Exercises on Some Functions of the Respiratory System and the Development of the Response and Speed of Movement of Water Polo Players
}

\author{
Raafat Mohamed Tawfiq Hamza \\ Aquatic Sports Training Department, Faculty of Physical Education, Abu Qir, Alexandria University - Egypt
}

\begin{abstract}
Research objectives - Developing the speed of motor response and motor speed using some specific exercises for the junior water polo players. - Improving the level of some important functions of the respiratory system for the junior water polo players. The experimental method was used on a sample of 28 junior players at Smouha Sporting Club in Alexandria. Most important conclusions and recommendations: - Using the complex specific exercises helps to develop the speed of motor response of the junior water polo players. - Using the complex specific exercises led to the development of the motor speed in the performance of some important offensive and defensive techniques of the junior water polo players. - The development of the speed of motor response and motor speed and the efficiency of the respiratory system led to an obvious improvement in the level of performance of the junior water polo players. The researcher recommended: - Developing the speed of motor response and improving the functions of the lungs of the water polo players in the training early stages because the training in late stages needs a longer time and more effort of the players and the trainers. - Using the specific training and techniques under consideration in developing the speed of motor response and motor speed of the junior water polo players. - Improving the efficiency of the vital organisms, especially the respiratory system, to delay the emergence of fatigue among the water polo players.
\end{abstract}

Introduction and importance of the research:

$\mathrm{W}$ ater Polo is an interesting aquatic sport for both practitioner and viewer. The beauty of this game is that it combines two great sports at the same time, which are swimming and handball, so the practitioner enjoys a lot of physical and motor fitness. It is a team sport that develops cooperation and team spirit and it is also considered a recreational game just like other aquatic sports that bring joy and pleasure.

It requires the players to swim for a long time and in repetitive different distances in addition to the physiological efficiency of some functions of the respiratory system and the ability to swim at repetitive different speeds at a high level of motor response and technical performance from the players in order to implement the offensive or defensive techniques.

Kevin Ball (2003) pointed to the motor speed as one of the important characteristics of the water polo player especially during the game due to the need of the player to perform movements and repetitive frequencies (12:33)
Mufty Ibrahim Hammad (2001) defined the motor speed as the achievement of more than one motor technique in the least possible time (18:26)

It was also defined by Essam Abdel-Khalek (2005) as the ability of the player to perform a specific motor duty in the shortest possible time, the speed of muscular contraction followed by a series of motor contractions (12:168)

There are many techniques that need effort and endurance from the players, such as the technique of pedaling in water. Michelle Pikering et al., (2007) states that this technique allows the players to maintain stability, balance, head stability over the water and the position of the body. The technique is performed to cut or block the goal or cut the cross pass (32:45)

Specific exercises can improve the performance of water polo players, as Abdel-Aziz El-Nemr and Nariman ElKhatib (2000) showed that muscular strength training must be related to intensive training when performing the move using the proper technical performance that achieves the synchronization between power and speed to develop a high degree of motor compatibility (10:166) 
Ebben et al., (2000) Duthie et al., (2002) conform that specific exercises are auxiliary exercises designed to create and develop the motor techniques according to the type of sports activity in an attempt to shape and build the body in proportion to the techniques requirements $(30: 451)(29: 530)$

The researcher identifies the complex specific training as a set of specific exercises similar to the performance of the movement in the form of a technique to be performed and repeated during the water polo games, so by training on the performance of these techniques, the players can use them during the games to achieve better performance.

Aly Fahmy El-Beik et al. (2008), citing Brown (1996), states that most special athletes possess great strength and speed and have the ability to link between these two elements in an integrated form in order to achieve the best performance of different techniques using exercises that combine the two components of muscular strength and speed, and this is better than training the two components of muscular strength and speed separately (18:20)

Mamdouh El-Shennawy (1995) notes that the low level of Egyptian players is due to the low level of passing and correction, the players' blocks, the goalkeepers' level and the low level of techniques required to encounter and tackle whether the techniques are offensive or defensive $(22: 27)$

According to Hanafy Mahmoud Mukhtar (1999), analyzing and assessing the player's performance and the team as a whole is an important means to develop the performance whether the player or the team won or lost in their competitions. The main duty of the technical manager is to analyze the games and obtain certain conclusions as a result of the objective observation, which is an important means to assess and review the progress of the game and its results as well as the impact of training on the players' performance during the match as individuals and as a group and then a team since the competition is the real test to measure the success of the training process $(7: 282,283)$

Mohamed Sobhy Hassanein and Hamdy Abdel-Moneim (1997) note that the importance of the game analysis method is the integrated system for evaluation and measurement, whether for the player or the team, in the training or competitions and thus it is a system that enables:

- the individual's own comparison where these procedures help following up the levels of the individual and the extent of achieved progress.
- comparing the individual to his peers as this leads to increasing the motivation and knowledge of the real strengths of the team.

- comparing the team with other teams (24:47)

The researcher observed through the level of performance of some teams in the Egyptian water polo that there were signs of fatigue on the Egyptian players compared to some European clubs and that the performance of the players in the first four minutes of the game was better than the four minutes at the end of the quarter, and he realized that the weak efficiency of the functions of the lungs, the slow implementation of the attacks and the delay of defense as a result of the low level of motor response and motor speed of the players so the speed of motor response and motor speed of players should be improved.

\section{Research problem}

The speed of motor response and motor speed have an important role in raising the level of technical performance, especially for the junior players, since the team with the fast motor response can overcome the competitor and perform various techniques with high efficiency and work on confusing the players of the opposing team because of the sudden performance and make them lose sufficient time to defend the ball and in turn leads to scoring goals.

The researcher observed by monitoring the local and international championships that there is a weakness in the speed of the motor response of the Egyptian players especially the goalkeepers in addition to fluctuation of performance while fatigue starts to emerge and decreasing functional efficiency, these were the reasons the researcher aimed to study the effectiveness of some specific exercises so that it can develop the speed of the motor response of the players and raise the level of efficiency of some functions of the lungs as one of the vital and important organisms that helps delaying the emergence of fatigue on the players and the ability to bear the burden of the game and achieve the highest possible level of performance during the game quarters.

The research problem focuses on the slow speed of the motor response of the players and the slow implementation of the techniques, which negatively affects their performance. The aim of the research is to develop the level of speed of response and the motor speed and improve the functions of the respiratory system so as to achieve the highest possible level of performance for the Egyptian players. 


\section{Research objectives}

- Developing the speed of motor response and motor speed using some specific exercises for the junior water polo players.

- Improving the level of some important functions of the respiratory system for the junior water polo players.

\section{Research hypotheses}

The researcher hypothesizes:

- some of the complex specific exercises can improve the speed of motor response and motor speed of the junior water polo players.

- some of the complex specific exercises can improve some of the important respiratory functions of the junior water polo players

\section{Literature review}

Many previous studies including Radcliffe and Radcliffe 1999. Hussein Abaza 2003, Mohamed Ashmawi 2003, Alaa Qenawi 2005 and Aly Ibrahim 2014, that the complex training method accelerates the process of development and performance improvement and the results were positive. Nahida Al-Dulaimi, Aida Al-Amir 2010 and Mohamed Ahmed Aly 2012 also proved the importance of specific training in improving the technical performance and developing some physical and motor characteristics of the swimmers as well as for some other sports (34:189) (6:15) (12:21) (12:14) (10:17) (13:28) $(20: 44)$

\section{Research domains}

Spatial domain: Smouha Sporting Club in Alexandria

Temporal domain: duration from 3/5/2017 to 7/7/2017.

Research methodology: the experimental method was used with the design (experimental group and control group) for its relevance to the nature of the research.

Research sample: the research sample was purposively selected from the water polo junior players and the total sample strength consisted of 28 players and were divided into two groups with 14 players each.

1- The experimental group applied the complex specific training to develop the speed of motor response and the level of some functions of the respiratory system.

2- The control group used the team coach's method.

\section{Sample homogeneity:}

The sample homogeneity was proved in the main variables (age, height and weight) by calculating the contortion coefficient for the outcomes of the sample as shown in table (1)

Table (1)

The sample homogeneity

\begin{tabular}{|c|c|c|c|c|c|}
\hline Variables & Measruing unit & Arithmetic mean & $\begin{array}{c}\text { Standard } \\
\text { deviation }\end{array}$ & Frequency & Contortion coefficient \\
\hline Age & year & 14.9 & 1.23 & 14 & 0.93 \\
\hline Height & $\mathrm{cm}$ & 176.16 & 1.39 & 177 & 0.88 \\
\hline Weight & $\mathrm{km}$ & 68.44 & 1.81 & 67 & 0.78 \\
\hline Training age & year & 5.70 & 0.55 & 5.60 & 0.55 \\
\hline
\end{tabular}

Table (1) shows that the values of the contortion Equivalence of the two research groups: in order to ensure coefficient are smaller than $(+1)$ indicating that the sample members are homogeneous in the main variables (age, height and weight) the equivalence of the two groups, $T$ test was used in the equivalence process to determine the differences as shown in table (2). 
Table (2)

Equivalence of the two research groups

\begin{tabular}{|c|c|c|c|c|c|c|}
\hline \multirow{2}{*}{ Measurements } & \multirow{2}{*}{ Measuring unit } & \multicolumn{2}{|c|}{ Experimental group } & \multicolumn{2}{|c|}{ Control group } & \multirow{2}{*}{$\begin{array}{l}\text { Calculated T } \\
\text { value }\end{array}$} \\
\hline & & $\mathbf{X}-$ & $+\mathbf{P}$ & $\mathbf{X}-$ & $+\mathbf{P}$ & \\
\hline Total length & $\mathrm{cm}$ & 176.5 & 0.78 & 0.11 & 0.59 & 0.11 \\
\hline Length of the leg & $\mathrm{cm}$ & 94.68 & 0.69 & 0.70 & 0.92 & 0.70 \\
\hline Length of the arm & $\mathrm{cm}$ & 77.72 & 1.50 & 0.38 & 1.65 & 0.38 \\
\hline Vital capacity & liter & 4.555 & 0.229 & 0.25 & 0.221 & 0.25 \\
\hline Number of breathing times & times / min. & 16 & 0.894 & 0.57 & 0.547 & 0.57 \\
\hline Pulmonary ventilation per minute & liter / $\min$. & 6.359 & 0.325 & 0.261 & 0.291 & 0.261 \\
\hline $\begin{array}{l}\text { Technical performance of the } \\
\text { complex technique }\end{array}$ & degree & 4.97 & 1.39 & 0.41 & 1.53 & 0.41 \\
\hline Speed of motor response & second & 3.92 & 0.84 & 0.41 & 0.68 & 0.41 \\
\hline
\end{tabular}

Table (2) shows that the calculated $\mathrm{T}$ values in all of the measurements are smaller than the tabulated value (2.23) with significance level $(0.05)$, therefor the differences were not equivalent.

\section{Means, tools and devices used}

\section{Data collection tools:}

- Arabic and foreign sources and references

- Observation and experimentation

- Technical tests and motor response test

Tools and devices used:

- 25m swimming pool

- (10) legal water polo balls

- Measuring tape

- Adhesive tape, a whistle and a stopwatch

- Technical evaluation form for the complex technique

- Esperometer to measure the lung's function

- Application forms for the players' data

- Camera

- Computer

- $23 \mathrm{~m}$ wooden blocks

- Ropes and poles

- 2 goal nets

- Flags and whistles

Pilot experiment: in order to control the variables of the research and identify the obstacles to work and to ensure the success of implementing the scpecific exercises, the researcher conducted a pilot experiment before the main experiment of the research on a sample not included in the main sample to conclude the following:

1- examining the relevance of the training and tests for the research sample

2- determining the time taken to perform the exercises and tests

3- examining the relevance of the tools and devices in the research

4- determining the obstacles that the researcher may face

Scientific treatments of the tests: (validity, reliability and objectivity) for the tests of the technical performance of the complex technique and the speed of motor response and motor speed test as follows:

Validity of the tests: the intrinsic validity was reached, and it represented the root of reliability coefficient as shown in table (3)

Reliability of the tests: reliability coeffcient was confirmed for the tests of technical performance of the complex technique the the speed of the motor response test by re-testing as the test was applied on the sample of the pilot experiment and then was re-tested and by using Pearson correlation coefficient (Spearman), reliability coeffcient was reached as shown in table (3)

Objectivity of the tests: objectivity coeffcient for the tests under study was obtained through the evaluation of specialized and experienced judges and the simple correlation coefficient between them was found as shown in table (3) 
Table (3)

The scientific treatments of the technical performance tests of the complex technique and the speed of motor response test

\begin{tabular}{|c|c|c|c|}
\hline Scientific treatments & Reliability coefficient* & intrinsic validity coefficient & Objectivity coefficient \\
\hline Test of the technical performance of the complex technique & 0.91 & 0.95 & 0.96 \\
\hline Speed of motor response test & 0.94 & 0.90 & 0.93 \\
\hline Motor speed test & 0.89 & 0.91 & 0.94 \\
\hline
\end{tabular}

* Tabulated $\mathrm{T}$ value at freedom degree (4) and significance level $0.05=0.81$

\section{Research application:}

The tests were conducted on 3/5/2017 and the selected training exercises were applied to the experimental group members and the training program was applied by the team coach to the control group from $5 / 5 / 2017$ to $6 / 7 / 2017$ and the post-measurements were conducted on 7/7/2017 and included the specific training phases in the main part of the module. Table (4) shows the time distribution of the program.

Table (4)

Time distribution of the program

\begin{tabular}{|c|c|c|}
\hline S. & Content & Total and time \\
\hline $\mathbf{1}$ & Number of weeks of the program & 8 \\
\hline $\mathbf{2}$ & Number of training modules & 24 \\
\hline $\mathbf{3}$ & Total number of modules & $8 \times 3=24$ \\
\hline $\mathbf{4}$ & Training time (resistance exercises, water lengthening and specific exercises) & 120 min. \\
\hline
\end{tabular}

\section{Statistical treatments:}

In order to process the statistical data, the following statistical treatments were used:

- Arithmetic mean

- Standard deviation
- Contortion coefficient

- Correlation coefficient (Spearman)

- T test

Presentation, analysis and discussion of the results:

Table (5)

Arithmetic means, standard deviations, calculated T test outcomes between the pre- and post- tests of the experimental group

\begin{tabular}{|c|c|c|c|c|c|c|}
\hline \multirow[b]{2}{*}{ Tests } & \multirow{2}{*}{ measuring unit } & \multicolumn{2}{|c|}{ Pre-test } & \multicolumn{2}{|c|}{ Post-test } & \multirow{2}{*}{$\begin{array}{c}\text { Calculated T } \\
\text { value }\end{array}$} \\
\hline & & $\mathbf{X}-$ & $+\mathbf{P}$ & $\mathbf{X}-$ & $+P$ & \\
\hline Vital capacity & liter & 4.555 & 0.229 & 5.603 & 0.221 & 5.603 \\
\hline Short exhalation in the first second & liter & 3.355 & 0.098 & 5.196 & 0.193 & 5.196 \\
\hline Number of breathing times & times / min. & 16 & 0.894 & 6.708 & 0.547 & 6.708 \\
\hline Pulmonary ventilation per minute & liter / min. & 6.359 & 0.325 & 10.061 & 0.291 & 10.061 \\
\hline Speed of motor response (Nelson) & second & 3.92 & 0.84 & 3.78 & 0.42 & 3.78 \\
\hline Technical performance of the technique test & degree & 4.97 & 1.39 & 4.16 & 0.65 & 4.16 \\
\hline Endurance of the complex technique & second & 35.45 & 1.98 & 4.49 & 2.17 & 4.49 \\
\hline Motor speed test & number & 5.1 & 1.88 & 3.96 & 2.41 & 3.96 \\
\hline
\end{tabular}

The findings of table (5) showed that the calculated $\mathrm{T}$ the tabulated $\mathrm{T}$ value at (2.57) with freedom level (5) and values between the pre-tests under study were greater than significance level (0.05) 
Table (6)

Arithmetic means, standard deviations, calculated T test outcomes between the pre- and post- tests of the control group

\begin{tabular}{|c|c|c|c|c|c|c|}
\hline \multirow{2}{*}{ Tests } & \multirow{2}{*}{ measuring unit } & \multicolumn{2}{|c|}{ Pre-test } & \multicolumn{2}{|c|}{ Post-test } & \multirow{2}{*}{$\begin{array}{l}\text { Calculated T } \\
\text { value }\end{array}$} \\
\hline & & $\mathrm{X}-$ & $+\mathbf{P}$ & $\mathrm{X}-$ & $+\mathbf{P}$ & \\
\hline Vital capacity & liter & 4.420 & 0.310 & 2.521 & 0.266 & 2.521 \\
\hline Short exhalation in the first second & liter & 3.341 & 0.142 & 3.098 & 0.148 & 3.098 \\
\hline Number of breathing times & times / min. & 15.666 & 0.816 & 2.236 & 0.752 & 2.236 \\
\hline Pulmonary ventilation per minute & liter / min. & 6.135 & 0.378 & 4.612 & 0.558 & 4.612 \\
\hline Speed of motor response (Nelson) & second & 4.08 & 0.68 & 3.09 & 0.37 & 3.09 \\
\hline Technical performance of the technique test & degree & 4.26 & 1.53 & 3.14 & 0.94 & 3.14 \\
\hline Endurance of the complex technique & second & 36.37 & 1.62 & 3.29 & 2.78 & 3.29 \\
\hline Motor speed test & number & 5.2 & 2.10 & 2.3 & 2.41 & 2.3 \\
\hline
\end{tabular}

The findings of table (6) showed that the calculated T level (5) and significance level (0.05) and this shows that values between the pre- and post-tests under study were there is significant difference in favor to the post-tests. greater than the tabulated $\mathrm{T}$ value at (2.57) with freedom

Table (7)

Arithmetic means, standard deviations, calculated T test outcomes of the post-tests between the experimental and control groups

\begin{tabular}{|c|c|c|c|c|c|c|}
\hline \multirow[b]{2}{*}{ Tests } & \multirow{2}{*}{ measuring unit } & \multicolumn{2}{|c|}{ Experimental group } & \multicolumn{2}{|c|}{ Control group } & \multirow{2}{*}{$\begin{array}{c}\text { Calculated T } \\
\text { value }\end{array}$} \\
\hline & & $\mathrm{X}-$ & $+\mathbf{P}$ & $\mathrm{X}-$ & $+\mathbf{P}$ & \\
\hline Vital capacity & liter & 4.815 & 0.221 & 4.538 & 0.266 & 4.45 \\
\hline Short exhalation in the first second & liter & 3.655 & 0.193 & 3.421 & 0.148 & 5.71 \\
\hline Number of breathing times & times / min. & 14.50 & 0.547 & 15.166 & 0.752 & 5.63 \\
\hline Pulmonary ventilation per minute & liter / $\min$. & 8.347 & 0.291 & 6.785 & 0.558 & 5.14 \\
\hline Speed of motor response (Nelson) & second & 2.65 & 0.42 & 3.36 & 0.37 & 2.84 \\
\hline Technical performance of the technique test & degree & 8.98 & 0.65 & 6.25 & 0.94 & 3.86 \\
\hline Endurance of the complex technique & second & 62.73 & 2.17 & 53.41 & 2.78 & 5.91 \\
\hline Motor speed test & number & 9.4 & 2.10 & 6.2 & 2.41 & 3.81 \\
\hline
\end{tabular}

The findings of table (7) showed that the calculated $\mathrm{T}$ values between the pre- and post-tests were greater than the tabulated $\mathrm{T}$ value at (2.57) with freedom level (5) and significance level (0.05) and the significant difference and this shows that there is significant difference in favor to the experimental group.

\section{Discussion of the results:}

The findings of tables (5, 6 and 7) show significant differences between the pre- and post-tests in fvor to the post-tests and the experimental and control groups. The researcher explains the difference of the control group to the coach's training method which includes physical and motor exercises that depend on strength, speed and agility that have played a "fundamental" role in the development of technical performance, and the interpretation of that improvement in the physiological variables of the control group due to the physical effort of the members of the control group as the regular training help achieving physiological effects in the body's vital organisms and this conforms to Mohamed Samir Saad-Eldin 2000 when he noted that physical activity leads to increased cardiovascular activity and higher rate of Oxygen extraction in the pulmonary vesicles $(23: 116)$

The efficiency level of the functions of the respiratory system was not at a high level compared to the group that used the complex specific exercises and there were greater significant differences in the experimental group which was believed by the researcher the differences were a result to the effectiveness of the complex exercises, which led to a significant improvement in performing the complex technique and development of the speed of motor response and motor speed. There was also a significant improvement in the results of the measurements of the lungs' functions as a result of using the complex specific exercises and they was relevant to the type and specificity of the techniques and the players' level. Using the complex specific exercises for the motor response, motor speed and complex technical performance of the water polo led to the excitement during the performance and the state of boredom was removed among the players so that they were motivated to achieve the best performance as 
Essam Helmy 1997 noted that the motor performance is the objective measurement which is based on the player's performance to any technique (13:340)

The motor performance of the technique depends on the special physical abilities and this was confirmed by Essam Abdel-Khalek 1994 that "special exercises are not an alternative method of training, but a very important method" that can not be dispensed with and also has an effective role during the period of special preparation, so we should not consider the specific exercises is not feasible, but it is a method of multiple requirements technically, physically and functionally as well (11:66)

Mohamed Aly El-Kot confirms that in order to develop the functional aspects, the training programs should be built to achieve the development of special physiological abilities required to perform the sports activity. This is called the principle of specialization (12:25)

Samir Rezk, 2003, showed the importance of the respiratory measurements that athletes should take into consideration "showing their physical readiness for heavy motor activity, which requires large amounts of air and expulsion of carbon dioxide (8:35)

Abou-Elela Abdel-Fattah points that applying the dynamic physiological tests of the lungs to athletes is important and these tests are based on two factors: the volume of air moving in each breath and the speed of movement of the air. These are the short-term exhalation measurements of the first second and this is the volume of produced air per second, also the volume of air the lungs require between the first two seconds. Generally, the volume of air that comes out of the lungs during the first second ranges between $80-83 \%$ of the total exhale $(1: 369)$

Applying the complex specific training continuously helped correct the errors and allowed the players to reach their highest level and develop themselves as the player can perform the technique automatically by repetition.

Since the specific exercises are various and interrelated with a series of movements consistent with the performance and the application of the principle of gradient from simple to complex when giving specific exercises for agility helped to develop this trait and that the more agile the player was he would be able to quickly improve his level.

This conforms to Ebben et al. 2000 (27) that complex training is one of the best exercises used to improve ability, combining the benefits of different exercises $(30: 456)$
Aly Nassif 1998 also noted that in order to understand the motor duty to perform is the player's ability to respond to the surrounding stimuli, which are received by the sensory nerves to the cortex of the brain, then sent to the muscles by the motor nerves and respond to these stimuli as quickly as possible. The speed of the motor response depends on the reaction time which is "the period between the stimulus and the beginning of the response (19:107)

The complex specific exercises have been standardized in a form that allows developing the speed of motor response and improve the efficiency of certain functions of the lung, and this was indicated by Mohamed Hassan Allawy, Abou Elela Ahmed Abdel-Fattah, 2003 and Scoot 2001 as the success of the training curriculum lies in standardizing the training load to suit the physiological situation of the body $(1: 12)(22: 35)$

The implementation of complex specific exercises depends more on oxygen to supply the energy, and this is consistent with Amrallah Ahmed 2001 as he pointed that the direction of training is determined in terms of quantity, quality and style according to the energy supply system $(5: 49)$

The complex specific exercises have led to an obvious change in the efficiency of the lung's function and this confirms what Kassem Hussein, 1990, Aly Galal, 2007, and Ossama Riyad, 2003, who proved that regular exercises lead to positive changes in the respiratory system since these changes provide additional flexibility in the rib cage muscles, which increases the volume of inhaled air and thus helps to increase the amount of oxygen in the exchange of gases between blood and alveoli and reducing the breathing activity due to the vital capacity (9:134) $(16: 146)(3: 137)$

Ian Taylor and David Vear 1998 agree that the aim of the training process is to find the best ways to improve the player's achievement because the achievement is the focus of the training process $(31: 114)$

The results show an improvement in the count of breathing times as Ahmed El-Awady, 2006, and Ahmed Mahmoud El-Hamoury, 2003, show that adults inhale and exhale a range of 12 to 18 times per minute and the respiratory rate is the number of breathing times while in athletes the rate becomes less because training improves the efficiency of the breathing process as the athlete needs fewer breathing times to move the same volume of air $(15: 23)(2: 54)$

The repeated techniques and performed training led to physiological changes in the respiratory system, and that was shown in the results of endurance as explained by 
Esmat Abdel-Maksoud, 1997 that the individual and group performance require a high degree of endurance that enables the player to continue playing as a result of the rapid shift of play from attack to defense and vice-versa, in competitive, offensive and defensive performances $(4: 65)$

The player's ability to perform hard movements for a long time and maintaining them without the decline in the effectiveness of techniques helps the player to maintain the physiological processes at a high level under the conditions of the work of oxygen.

\section{Conclusions and recommendations:}

\section{I- Conclusions:}

- Using the complex specific exercises helps to develop the speed of motor response of the junior water polo players.

- Using the complex specific exercises led to the development of the motor speed in the performance of some important offensive and defensive techniques of the junior water polo players.

- Using the complex specific exercises led to an obvious improvement in the efficiency of some of the respiratory functions of the junior water polo players.

- The development of the speed of motor response and motor speed and the efficiency of the respiratory system led to an obvious improvement in the level of performance of the junior water polo players.

\section{II- Recommendations:}

Based on the conclusions, the researcher recommends the following:

- Developing the speed of motor response and improving the functions of the lungs of the water polo players in the training early stages because the training in late stages needs a longer time and more effort of the players and the trainers.

- Using the specific training and techniques under consideration in developing the speed of motor response and motor speed of the junior water polo players.

- Improving the efficiency of the vital organisms, especially the respiratory system, to delay the emergence of fatigue among the water polo players.

- Giving interest to the motor characteristics along with the technical and planning aspects for their importance during the different playing positions in water polo.
- Conducting further research and studies to help improve the efficiency of vital organisms and other motor characteristics in the field of water polo and other aquatic sports as well.

\section{References:}

1- Abu El-Ola Abdel-Fattah (2003): physiology of training and sports. Cairo. Arab Thought House

2- Abd el Aziz Al-Nimr and Nariman Al-Khatib (2000): Physical preparation and weight training for pre-puberty youth, professors for publishing and distribution

3- Ahmed Mahmoud Hamouri (2003): The Effect of a Proposed Training Program on Some Physiological and Physical Variables of Volleyball Players, Unpublished Master Thesis, Yarmouk University, Irbid.

4- Alaa Mohammed Mahmoud Qenaoui (2005): Effectiveness of the functional force training on some physical variables and the level of performance of the movement of the center of the opposite of junior wrestlers published research, Journal of the Faculty of Physical Education for Boys, Zagazig University.

5- Ali Ahmed Naguib Al-Awadi (2006): Effect of Proposed Oxygen Training Program on Some Physiological Variables in Patients with High Blood Pressure in Diwaniyah Governorate, Unpublished Master Thesis, Yarmouk University, Irbid, Jordan

6- Ali Jalal el ddin (2007): Principles of Functions of Members. Cairo . Pharaohs

7- Ali Fahmy Al-Beek, Others (2008): A Series of Recent Trends in Mathematical Training - Theories, Applications, Methods and Methods of Training for the Development of Anaerobic and Pneumatic Capabilities, Part 3, Knowledge Facility, Alexandria

8- Ali Ibrahim Shibut (2014): Effect of the use of composite training in the low frequency method of rehabilitation of athletes with muscular weakness of the lower limbs, Journal of Physical Education, Volume 13, No. 2, University of Baghdad

9- Ali Nassif (et al) (1990): Fencing, Baghdad: Dar alHikma Press.

10- Amer allah Ahmad Al-Bassati (2001): Physical training - career in football Alexandria, the new university publishing house.

11- Duthie, G.M., Young, W.B. and Aitken, D.A (2002(: The acute effects of heavy loads on jump squat performance: an evaluation of the complex and contrast 
methods of power development. Journal of Strength and Conditioning Research 16 (4) p530-538.

12- Ebben, W. P., Watts, P. B., Jensen, R. L. and Blackard, D.O (2000): EMG and kinetic analysis of complex training exercise variables. Journal of Strength and Conditioning Research 14(4), 451-456.

13- Essam Abdel Khalek (1994): Mathematical Training Theories of Applications, I 1, Alexandria: Dar Al Ma'arif

14- Essam Abdel Khalek (2005): Mathematical Training Theories of Applications, I 12 Cairo, Arab Thought House.

15- Essam Mohamed Amin Helmi (1997): Mathematical Training, Foundations, Concepts, Directions, Alexandria Dar Al Ma'arif

16- El sayed Abdel Maqsoud (1997): Theories of Mathematical Training and Force Physiology, The Book Center for Publishing. Cairo

17- Hussein Abaza (2003): Effectiveness of compound training on bone mineral density, catecholamine pole and digital achievement of swimmers, Journal of Faculty of Education, Ain Shams University

18- Hanafi Mahmoud Mukhtar (1999): Director of Football, Al-Kuttab Publishing Center, Cairo

19- Keven Ball. (2003): an over view of the fundamentals of water polo, http // coachesifo . com.

20- Lan Taylor with David Vear (1998): Taylor on hockey, firest published, Greater House , London.

21- Michelle pikering, Guy baker , \& Tom seitz \& brad Schumacher (2007): u s a water polo menes and womanes athlet selection procedure $\mathrm{u} s \mathrm{a}$

22- Mohammed Ahmed Ali Al-Halaf (2012): Effect of the use of specific exercises on the skill of swimming and swimming to improve the performance of swimming free for the swimmer Master of the Faculty of Physical Education for Boys Benha University

23- Mohamed El-Sayed Ashmawy (2003): Effect of some special exercises on the level of physical and skilled performance of the movement of the center and lifting the curve of the wrestlers, Master Thesis, Faculty of Physical Education for Boys, Zagazig University.
24- Mohamed Ali Ahmed Al - Qatt (1999): The functions of members of the training of the athlete in the application, Dar Al - Fikr Al - Arabi, Cairo

25- Mohamed Hassan Allawi, Abu El Ela Ahmed Abdel Fattah (2000): Physiology of training and sports. Cairo. Arab Thought House.

26- Mamdouh Al-Shennawy (1995): Effect of the development of the muscle strength of the two men on some kinematic variables for water polo players. Master Thesis unpublished Faculty of Physical Education in Port Said for Boys Suez Canal University

27- Mohammed Samir Saad Eddin (2000): Physiology and Physical Effort. I. Cairo. Dar Al Ma'arif

28- Mohamed Sobhy Hassanein and Hamdi Abdel Moneim (1997): The Scientific Basis of Volleyball, Methods of Measurement and Evaluation, The Book Center for Publishing, Cairo

29- Mufti Ibrahim Hammad (2001): Modern Sports Training Application Planning and Leadership, 2 Cairo, Dar Al-Fikr Al-Arabi.

30- Nahida Abdel Zaid Al-Dulaimi, Aida Hussein Abdel Amir (2010): The impact of qualitative exercises in the development of speed of motor response and skillful performance of the overwhelming beating of volleyball players Issue I Volume III

31- Osama Riyad (2003): Sports Medicine and Athletics. Cairo University. Arab Thought House

32- Radcliffe, J.C. and Radcliffe, J.L. (1999): Effects of different warm-up protocols on peak power output during a single response jump task. Medicine and Science in Sport and Exercise 38(5), S189.

33- Scoot K. Edwers, T. Houley, (2001): Exercise physiology Theory and Application to Fitness and performance. 4ed, published by mecraw- Hill.

34- Samir Abdullah Rizk (2003): The scientific encyclopedia of swimming sport. Amman.

35- Qasem Hassan Hussein (1990): physiology and its applications in the field of sports connector. Dar $\mathrm{Al}$ Hekma for Printing and Publishing. 